\title{
Analyzing Motivation Factors for NASCAR Spectators with Self-Determination Theory
}

\author{
Yayun Liu ${ }^{1}$, Leon Chen ${ }^{1, *}$, Xiaofen Keating ${ }^{2}$, Mark Still ${ }^{3}$, Shihui Chen ${ }^{4}$ \\ ${ }^{1}$ College of Physical Education, Hunan University of Technology, Hunan, China \\ ${ }^{2}$ Department of Curriculum Instruction, University of Texas, Austin, USA \\ ${ }^{3}$ Department of Sport Management, Delaware State University, Dover, USA \\ ${ }^{4}$ College of Education, Texas A \& M University, Texarkana, USA
}

Email address:

lchen@desu.edu (L. Chen), lchen20042003@yahoo.com (L. Chen)

${ }^{*}$ Corresponding author

\section{To cite this article:}

Yayun Liu, Leon Chen, Xiaofen Keating, Mark Still, Shihui Chen. Analyzing Motivation Factors for NASCAR Spectators with Self-Determination Theory. American Journal of Sports Science. Vol. 7, No. 3, 2019, pp. 78-87. doi: 10.11648/j.ajss.20190703.11

Received: March 10, 2019; Accepted: June 10, 2019; Published: July 30, 2019

\begin{abstract}
Research in consumer motivation might ignore auto racing sport that features the number one of fan attendance for single sport event in America. What would be the explicit motives to push individuals themselves or the incentives to pull the spectators with attractive benefits of NASCAR events? If motives exist among the NASCAR fans, would there be a need to discover them with an appropriate measurement tool? This study was conducted to explore specific motives of NASCAR spectators, and develop valid and reliable instrument underlying motivational theories. Participants $(N=650)$ voluntarily responded to Inventory of Motivation for Auto Racing Spectators (IMARS) in a NASCAR event. Exploratory and Confirmatory Factor Analyses were utilized to explore and confirm the 5-factor (Affiliation, Experience, Gratification, Socialization, and Substance) model with 15 indicators. The statistical analyses revealed acceptable goodness fit indexes of IMARS by the observed data $\left(X^{2} / d f=3 / 63, \mathrm{GFI}=.95, \mathrm{CFI}=.92, \mathrm{IFI}=.91, \mathrm{RMSR}=.036\right)$. The validities and internal consistency reliability were examined with satisfactory results. The essential motives were explored in this study and a reliable instrument for utility of NASCAR marketing professionals was produced. The study provided quantitative evidences to support the motivation theories and enriched spectator motivation in sport motivation literatures.
\end{abstract}

Keywords: NASCAR, Spectator Motivation, Self-determination Theory

\section{Introduction}

Auto racing competition has been challenging the top three professional sports in America and draws average 85 million fans per year to the racetracks for their leisure time. [1] National Association for Stock Car Auto Racing (NASCAR) reported that the fans have filled the seats over 1,500 races in nearly 40 states across America and other countries (Canada, Japan, Australia, Mexico) for major competitions (e. g, Sprint Cup, Camping World Truck Series) and various regional racing series. [2] Accordingly, the auto racing sport has been ranked the number one of fan attendance in single sport event, the number two in regular season sport television viewership, and the number three in the licensed sales among major professional sports in the United States. [1, 3, 4] Researchers of sport economics cited that auto racing was the most influential sport and provided significant economic impacts to the nation and region. [3, 4] For instance, the overall economic impact to a region of South Carolina reached $\$ 46.22$ million for only two-weekend events. [3] The fans have contributed $\$ 6,762$ million to supporting near 50,000 jobs in the auto race industry and have paid more than three billion dollars to the licensed products and services each year. [1]

While researchers provided explicit evidences on tremendous impacts of economics from NASCAR events, studies of leisure and sport marketing have remained relatively silent in presentations of consumer motivation in the auto racing industry. [1, 3, 4] Even if the NASCAR spectators made the top crowd of single event in professional 
sports, limited research effort has been given to finding reasons of why the fans were willing to spend money for watching this particular sport. [3] In other words, what were the motives causing them to consume auto racing for leisure? What were the factors affecting their determination to attend the social events? How could the sport marketers collect and interpret the data and synthesize information for marketing decisions? In investigation of consumer behavior, particularly of such larger attendant population, there must be meaningful variables that would be different from other findings of spectator motivation as regards to their preferences and related to their psychological and social needs in the auto racing sport. Therefore, conducting an analysis of the motivational factors affecting the attendants of NASCAR events would be valuable.

\section{Theoretical Framework}

\subsection{Motivation Theory}

Motivation, in social psychological theories including Self-determined Theory (SDT), is generally comprehended as a psychological driving force that can stimulate or reinforce one's behavior. With the SDT framework Deci believed that theoretical divisions of human motivation could be either intrinsic or extrinsic. [5] Intrinsic motivation reflects the motive extent to which interest or enjoyment of doing something is initiated from the individuals themselves without any given pressure or external attraction. Intrinsic motivation has more to do with 'push factor' in which the inner forces from physiological and psychological needs push an individual to behave. [6] Extrinsic motivation, however, is derived from resources beyond individuals such as attractions of the tangible benefits or threats from external environment. It is an outcome oriented with the motives to attain awarded benefits, and relates closely to 'pull factor' in which external attraction pulls or causes individuals' action. $[6,7]$

Self-determination theory (SDT) also identifies human motivation within the social context and deliberates the degree to which an individual behaves at an optimal level of reflected individuals of options or outcome of their self-determination. [5] It explores that social and cultural factors could affect feelings of volition of people and initiatives for their quality of performance. [7] SDT contains four mini-theories accordingly: 'cognitive evaluation' refines that intrinsic motivation occurs only as an individual is competent and self-determined to act; 'organismic integration' explains integrative relationship between extrinsic and intrinsic motivation in the dichotomy with external, introjected, identified, and integrated tiers; and 'causality orientation' illustrates how individual differences exist with human tendencies toward self-determined behavior for fitting social environment. However, 'basic needs theory' posits fundamental human needs as motives related to physiological function and psychological satisfaction. In addition, the concept of 'goal contents' specifies the distinctions of both intrinsic (e.g., friendship, social interaction) and extrinsic (e.g., material, appearance) goals that could be contributable to affect desires of people. [7]

The intrinsic and extrinsic motivation theories have been widely applied to quantitative and qualitative research in sport settings from athletics in higher education to the qualitative study of coaches' perception. [8, 9] Chen summarized motivational factors affecting decision of individuals in sport organizations and conceptualized the relationship between intrinsic motives (push factors) and extrinsic incentives (pull factors) by submitting the theoretical notion: ' $\mathrm{D}=p$ (summarized motivation factors)', in which the decision (D) of the individual is depending on a probability $(p)$ of extrinsic incentives multiplying the summed motivation factors. [10] The higher the degree of combined disposition of inner motives and external incentives, the higher possibility of positive decision would be made by the individual. A group of researchers in sport consumer behavior spent their efforts on defining motivation factors affecting decisions of sport consumers in light of supporting the theories of motivation. Wann earlier promised importance of the motivation and provided empirical summarization of the motivation factors in sport including 'self-esteem', 'benefit', 'escape', 'entertainment', 'economic factors', 'group affiliation', and 'family needs. [11] Later, Wann, Schrader, and Wilson considered that sport spectators' behavior must relate to their motives in sport consumption. [12] Kahle, Kambara, and Rose discovered motives were important for the spectators of college football games. [13] They constructed several intrinsic motives ('attachment to a team', 'importance of winning') in their Fan Attendance Motivation. In a study to develop the Motivation of Sport Consumer, Milne and McDonald booked nine motivation factors that could reflect intrinsic and extrinsic motivation of sport participants. [14] Trail and James scrutinized preliminary studies and expressed their concerns of "weaknesses in content, criterion, and construct validity" (p. 108). [15] They suggested that 'achievement', 'acquisition of knowledge', 'escape', 'family', 'physical attraction', 'physical skill', and 'social interaction' were more appropriate as psychometric constructs reflecting actual motivation of sport spectators. [15]

\subsection{Previous Research}

The common characteristics of these studies were all sport spectators based research in support of motivation theories, development of the measuring instruments, or examinations with relative small participant size $(N=105$ to $N=354)$. However, these analyses differed from each other in either selection of statistical software, number of factors in measurement inventories, or various samples from different sports. Testing participants were chosen from university students or student-athletes, to the extension of spectators in professional baseball, collegiate football, and multiple sports including baseball, softball, and wrestling. [13, 15-18] It is understandable that the spectators coming to watch different competitions might share similar interests or varied in their preferences. For example, the individuals with needs to stay away from tired work or bored environment would choose to 
attend a sport event or an entertainment alike. [15] However, it might not be the case if the individuals whose motive was enjoyment of 'aesthetics' would like to watch the crazy running cars in an extremely noisy track with high probability of car crash. [16] Thus, motivation factors in the instrument should reflect nature of competition, in other words, it must be sport-specific to truly measure what it is supposed to measure.

Although auto racing shares many similarities with other sporting games, it may be unique for the fans' culture and mobility with distinctive language. The fans often exhibits unique insignia and have "camaraderie stems of common norms, values, and beliefs" (p. 73). [19] The event was viewed as masculine fights between good and evil but associated with feminine support. [20] Even if the fans are either deeply bonded to NASCAR or pledged to the 'affiliated' sport, they are strong family orientated to make auto racing the number one 'American sport'. [19, 21] While NASCAR fans demonstrate stronger brand loyalty than those are in other sports, they are often with their 'affiliated' drivers, teams, and sponsors. [19, 22] In such a noisy atmosphere made by scared sound of running engines it creates a high degree of external stimulus and gives a unique 'experience'. [22] Auto racing could have higher risk factor (car accident) than other sports that also provides distinctive entertainment value to 'gratify' oneself or others. [19] NASCAR events often occupy a whole weekend that allows the spectators to socialize fully with family members, peers, friends, or other fans. It is the longer duration that might generate more opportunities of 'socialization' among the fans. [2] The longer the time they could stay with the events, the more cost would be. The fans might estimate the costs against 'substance' of benefits (discounted ticket, parking, hotel, and gifts) obtained from the auto racing events. [22] Characteristics of auto racing fans were generally younger, more men (76\%) than women (24\%), and featured as white American sport. [21, 23, 24]

\subsection{Motivational Factors}

As important as traditional motivation theories, SDT suggests three components of motivation. 'Competence' reflects that sport fans might have been motivated to obtain specific knowledge and experience for their psychological needs. 'Relatedness' expresses that interacting with and gratifying others could be universal needs of fans in social environment. 'Autonomy', however, might reflect needs and urge of fans to the sport with their formed attitudes and be the representative of reactive individuals. [5] The decisions of many fans might be made on their mature evaluation based on their 'competence' to control learning outcome, interactive experience with people, and relative independent judgment and reaction to the environment of sport events. It is the combination of SDT conceptual components, previous research findings of spectator motivation, and unique characteristics of auto racing fans to convince us that a further determination of motivation among auto racing spectators deserves an essential attention. Therefore, the following specific motivation factors derived from SDT components would be taken into account:
Affiliation: it is an intrinsic motive that causes behavior of associating and connecting identical people with similar interests or friendship. [11] A key to 'affiliation' motive is the willingness of individuals to belonging group or others with same interests. [10] It functions as the connection between psychological and physiological states of individual and social interpretation of these states. [7] An individual has a sense of similar identity would accept others toward similar interests. [22] The brand and loyalty to the sport, or related services are high level of the identity initiated from the 'affiliation' motive due to their needs and desires. [14, 22]

Experience: this variable of motivation comprises benefits of knowledge and skills determined by individuals through observation or involvement in the given environment. [5] It is the subjective competence of individuals' experience and cognitive reasoning of environmental stimuli that initiate behavior of the individuals. [7] Because "the experience is the experience of truth" (p. 158), [5] sport fans can be motivated to learn more sport-specific knowledge or experience of their favorable sport competition in the atmosphere differed from television. Because sport consumers often apply their cumulative experience to consumption of a sport, [17] they could desire more updated knowledge or new experience through their involvement of the auto racing events. [22] So that immediate information received from the life events do enhance their experience, especially for the novices, and advance their level of satisfaction in consuming the sport.

Gratification: it is a self-determined motive in the related form of leisure, pleasure, excitement, and appreciation to hard work or achievement of oneself or others. [6] With this motivation, individuals could decide whether it is valuable to gratify themselves or others depending on their willingness of individuals to accept the values pulled from external factors. [6] Gratification contains a function of entertainment that an individual intends to be enjoyable in the desired activities depending upon their outcome of self-interpretation. [16] It also has the element of escape or diversion in which an individual voluntarily retreats him/herself from routine for a pleasure or rewarding his/her previous work. [11, 15] The bored or tired consumers from their work were likely to stay way for a need of relaxation by attending a sport event in addition to watching movies or enjoying music. [25]

Socialization: that is also a self-determined motivation mechanism to interact with members of society including family, peer group, organization, and profession. [5] Individuals could be either intrinsically or extrinsically motivated to seek leisure opportunities to enhance human relationship through social interaction with other spectators in the sport events based on their self-judged sociological and psychological benefits. [11, 12] Many individuals would like to interact with others in order to establish and facilitate their personal or professional relationship. [16] The fans in the sport stadium would like to develop and enhance their progress or growth by exchanging their ideas, knowledge, and experience through various platforms of interactions. [9, 15, 24]

Substance: this refers to extrinsic incentive and a tangible meaning or utilitarian matter. [10] The individuals with this 
motivation are typically attracted by material benefits including monetary substance, other given incentives, or ubiquitous merchandise such as promotional bags and T-shirts. $[9,12]$ The sport fans might estimate the costs against the total benefits including purchasing opportunities and various serves provided in the sport events. In fact, the material substance satisfies individuals' economic interests and the sport organizations have utilized tangible inducements to keep sport consumers staying loyal. [10] An example might be either the discounted tickets received by the spectators for obtaining either an excited experience (e.g., observing fights for championship or car crashes) or value-added benefits to purchase logoed merchandises and receive complimentary services. [1] Practically all of these specified incentives might encapsulate the nature of external motivation within the psychological and sociological context that might impact motivation of sport consumers.

With the conceptual framework and related components, 5-factor model has been drawn (see Figure 1) for this study. The decision of NASCAR consumers (left box) would be affected by universal intrinsic motive (affiliation) pushed by themselves (one direction line) for attendance (right circle) reflecting their needs and desires. The extrinsic incentive of 'substance' (e.g., economic, knowledge, utilitarian) would pull consumers' actions by the tangible benefits (two-way line). The attendance decision of individuals would be also affected by important self-determined factors of 'experience', 'gratification', and 'socialization' as derived from three elements of SDT (competence, relatedness, and autonomy) in the middle rectangle box. The individuals with their 'competence', cognitive evaluation of related elements (relatedness), and independent judgment (autonomy) would favorite their positive 'experience' to gratify themselves or appreciate others (gratification), and enhance their social interaction (socialization) in the racetrack (see Figure 1). Thus, an Inventory of Motivation for Auto Racing Spectators (IMARS) needs to be developed for exploring and testing proposed motivation factors related to auto racing spectators. Even if previous studies in NASCAR conducted on economic impact, social culture, competition rewarding system, brand loyalty, or social responsiveness, but no one was to explore spectator motivation. [3, 19, 21, 22, 23] It is important to apply the SDT framework and scrutinize specific motives causing the consumers' attendance to the racetracks as a means to filling a void of research literature of consumer motivation in the distinctive population of auto racing spectators.

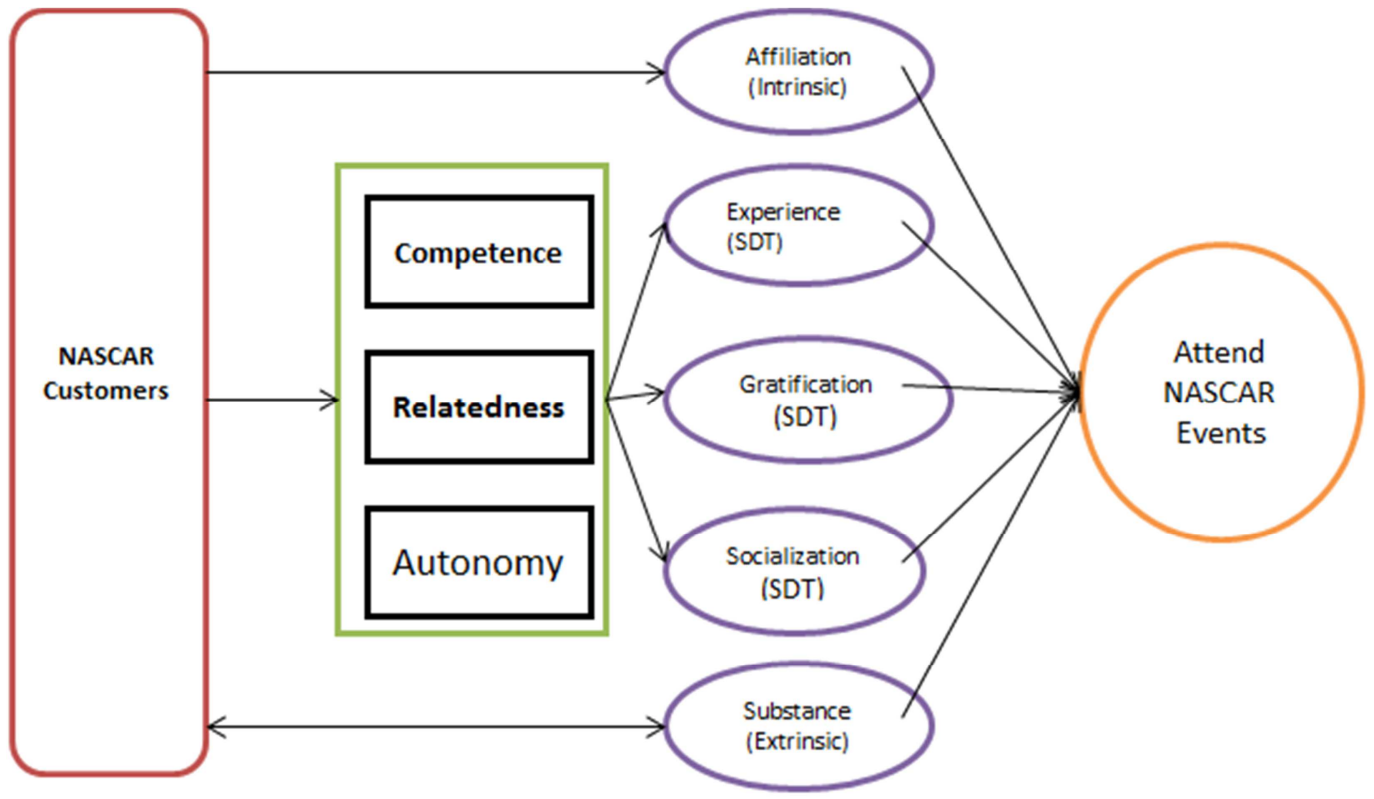

Figure 1. Proposed 5-Factor Conceptual Model for Motivation of Auto-Racing Spectators.

\subsection{Purpose of Study}

Previous research in sport consumer motivation have overlooked auto racing sport as advancing the largest fan population of the nation. Even though a number of instruments were out there for references, some were conceptually sound to construct models but demonstrated weaknesses due to lack of quantitative evidences. [15] Although many have exhibited sophisticated statistical application in developing the inventories, there might be questionable in their scholarly value because of weaken theoretical linkages. Neither the studies had a large sample pool, nor had attention paid to generalizability of the scales to fan populations of auto racing. [26] What would be the explicit motives to push individuals themselves or the incentives to pull the spectators with attractive benefits of NASCAR events? If motives exist among the NASCAR fans, would there be a need to discover them with an appropriate measurement tool? Therefore, the purpose of this study would be two folds: (a) to explore motivation factors of auto racing spectators relying on the contemporary motivation theories; \& (b) to examine validities and reliabilities of the items and factors constructed in IMARS for the model confirmation. 


\section{Materials and Method}

\subsection{Participants}

The participants $(\mathrm{N}=905)$ voluntarily involved in this study were randomly recruited from a major three-day NASCAR event in the east coast of the United States. Among them a total of 650 participants were finally identified by their completed survey packages ( $71.82 \%$ of effective response). The demographic information of participants contains Gender (female $=279$, male $=371$ ), Race (white $=569$, Africa-American $=32$, Hispanic $=10$, others $=39$ ), and Age (age 25 or below $=126$, age $26-35=232$, age $36-55=255$, age 56 or above $=37$ ).

\subsection{Procedure}

The study was conducted through three steps including content development, data collection, and data analysis. At the first step, a broad review of relative literature and interviews were conducted to generate theoretic foundation and imperial opinions for the model and instrument development. As a result Inventory for Motivation of Auto Racing Spectators (IMARS) was drafted. An expert panel including eight faculty of sport management, sport psychologist and the managers of NASCAR sport marketing were asked for content verification and assurance. With agreement rate $75 \%$ the content (face) validity was obtained. An initiative model of five factors (three derived from SDT components) including Affiliation (AFF), Experience (EXP), Gratification (GRA), Socialization (SOC), as well as Substance (SUB) and survey instrument containing 20 drafted motivation items were developed. The survey package contains informed consent, demographic information, and 20 -item survey questions led by "I attend the race because I like to ..." A 7-point scale was positioned at the end of each question (item). At the second step the predesigned survey packages were distributed to voluntary participants with assistance of faculty, management team of the facility, and trained sport administration graduate students at pre-set survey tables near three entrances and the exhibition area during a three-day NASCAR event. The spectators who were approaching the entrances and counted in even number were asked if they were willing to participate in the survey. Participants who agreed were given an explanation of the purpose of the research and then completed the survey voluntarily. A gift for appreciation was presented to the participant upon completion of the survey. The returned surveys were then interpreted and the data was entered into the computer database for analyses at the next step.

\subsection{Data Analyses}

With the content (face) validity satisfied in the first step of procedure, the step of data analyses involved that the effective data $(N=650)$ were retested in Exploratory Factor Analysis (EFA) and Confirmatory Factor Analysis (CFA), and construct validities and internal consistency (reliability) of IMARS in with the updated version Statistic Package for Social Sciences (SPSS) with AMOS 22.0. [27] The purpose of using EFA first was to reduce possible irrelevant items by examining interrelationships among items and "identify underlying factors or dimensions that reflect what the variables share in common" (p. 107) under its common factor analysis. It is also an essential statistical control before testing the data in CFA of Structure Equation modeling (SEM) for a new instrument development. [26] CFA was then used to further confirm the structure by specifying the indicators to the given latent constructs (factors), and examined whether conceptually sound factors and item specifications fit the expected model. [26] The construct validities including convergent and discriminate validities were tested to ensure the entire construct validity of IMARS. The alpha reliability analysis of SPSS with AMOS 22.0 was utilized to test the internal-consistency reliability for each factor. [27] The composite reliabilities and the average variance-extracted (AVE) measures were computed to assist examination of internal consistency of the IMARS constructs in verification of indicators accurately representing the latent constructs. [26]

\section{Results}

\subsection{Exploratory Factor Analysis (EFA)}

To use EFA the basic assumptions were tested in the SPSS with AMOS 22.0. [27] The magnitude of the Kaiser-Meyer-Olkin measure of sampling adequacy for original 20-item IMARS was .85 indicating an acceptable degree of common factor variance. The coefficient of Bartlett's test of Sphericity, indicating correlation magnitude differing from a given identity matrix, for the drafted scale was significant $\left(\mathrm{X}^{2}=4096, p<.05\right)$. The Common Factor Analysis was chosen to identify the latent contracts and eliminate specific and error variances. [27] Direct Oblimin rotation was then applied due to the nature of oblique rotation for the data, and testing the consistency of next CFA as the factors or latent constructs were inter-correlated. [27] The Delta was set as zero and cut-off point of factor loading (FL) was .50 for item deduction. Using specification of 5-factor solution, 15 items were retained and distributed to five factors (3 to 4 items for each) on the pattern matrix with FL ranging from .51 to .88 (see Table 1). Those items with FL lower than .50 or doubly loaded were eliminated.

The Eigenvalues of items ranged from 5.54 to .80 demonstrated that five factors had $36.93 \%$ to $5.28 \%$ variance contributing to the total variance of $70.81 \%$. The community $\left(\mathrm{h}^{2}\right)$ values ranging from .82 to .62 were satisfactory. [26] The explored five factors contained two to four items with higher correlations to the expected constructs underlying the proposal conceptual framework. The component correlation coefficients were $.310, .232, .403$, and .220 for AFF with GRA, EXP, SOC, and SUB; $.166, .188$, and .288 for GRA with EXP, SOC, and SUB; .372 and .132 for EXP with SOC and SUB; and .105 for SUB with EXP, respectively. The means, standard deviations, community values, and factor loadings of retained 15 items with 5-factor model are in Table 2. 
Table 1. Means, Standard Deviations, Community Values, Factor Loadings of 15 Retained Items of EFA $(N=650)$.

\begin{tabular}{|c|c|c|c|c|c|}
\hline Factors/Items & & $\mathbf{M}$ & SD & $h^{2}$ & FL \\
\hline \multicolumn{6}{|c|}{ I attend the race because I like to } \\
\hline \multicolumn{6}{|c|}{ Affiliation (AFF) } \\
\hline A-1 & Continue my life tradition of attending the races & 5.47 & 1.7 & .59 & .67 \\
\hline A-2 & Show my loyalty to my membership of sport club & 5.07 & 1.79 & .73 & .84 \\
\hline A-3 & Demonstrate a sense of belonging to my sport. & 5.13 & 1.75 & .70 & .75 \\
\hline \multicolumn{6}{|c|}{ Experience (EXP) } \\
\hline E-4 & Learn about NASCAR and auto racing (cars, rules). & 4.88 & 1.86 & .48 & .51 \\
\hline E-5 & Have an opportunity to witness the winners. & 4.62 & 1.89 & .73 & .85 \\
\hline E-6 & See the celebrities of the sport during the event & 4.75 & 1.94 & .77 & .83 \\
\hline \multicolumn{6}{|c|}{ Gratification (GRA) } \\
\hline G-7 & Get away from my daily grind and relax oneself & 5.76 & 1.54 & .57 & .68 \\
\hline G-8 & Gratify myself or guests during the entertainment & 5.64 & 1.38 & .51 & .66 \\
\hline G-9 & Enjoy my favorite driver and team & 5.37 & 1.83 & .80 & .83 \\
\hline \multicolumn{6}{|c|}{ Socialization (SOC) } \\
\hline S-10 & Have an enjoyable time with my family or relatives & 6.16 & 1.66 & 67 & 83 \\
\hline S-11 & Socialize with the fans, my friends, and peers & 5.98 & 1.38 & .62 & .80 \\
\hline S-12 & Get up close to my favorite driver or team & 4.83 & 1.91 & .74 & .65 \\
\hline \multicolumn{6}{|c|}{ Substance (SUB) } \\
\hline Su-13 & Take advantage of discounted tickets and parking & 4.46 & 1.94 & .70 & .88 \\
\hline Su-14 & Utilize great hospitality amenities around the area & 4.89 & 1.72 & .61 & .73 \\
\hline Su-15 & Consume the value added event packages (gifts, logoed wears, promotion items) & 4.77 & 1.86 & .60 & .70 \\
\hline
\end{tabular}

Table 2. Mean, Alpha, and AVE, and $R^{2}$ (in parentheses) Values, correlations and $R^{2}$ (in parentheses) Matrixes for IMARS $(N=650)$.

\begin{tabular}{lllllllll}
\hline $\mathbf{M}_{5}$ & M & $\boldsymbol{\alpha}$ & AVE & F1 & F2 & F3 & F4 & F5 \\
\hline Affiliation (AFF) & 5.22 & .85 & .68 & & & & \\
Gratification (GRA) & 5.59 & .70 & .59 & $.46^{*}(.21)$ & & & \\
Experience (EXP) & 4.75 & .82 & $.60(.26)$ & $.51^{*}(.09)$ & $.30^{*}$ & & \\
Socialization (SOC) & 5.67 & .72 & $.66(.11)$ & $.33^{*}(.29)$ & $.54^{*}(.21)$ & $.46^{*}$ & & \\
Substance (SUB) & 4.70 & $.70(.16)$ & $.58(.05)$ & & $.40^{*}(.05)$ & $.24 *(.04)$ & $.22 *$ & .21 \\
\hline
\end{tabular}

*correlation is significant at .05 level.

\subsection{Confirmatory Factor Analyses (CFA)}

The finalized 15-item data $(N=650)$ of EFA were further confirmed in CFA to validate the constructs of the model by using statistical software of SPSS with AMOS 22.0. [27] The normality of data was examined and the values of normalized multivariate skewness (85.00) and kurtosis (28.00) were both significant $(p<.05)$ demonstrating slightly multivariate non-normality. [27] Therefore, the Asymptotic Distribution Free with Weight Least Square was selected for the analysis. $[27,28]$

Submitting 15 indicators (items) to each of the expected five latent constructs (Figure 2), the CFA revealed standardized coefficients (factor loadings), measurement errors (Theta Delta) associated with indicators, and inter-factor correlation estimates (see Table 2). The standardized coefficients ranging from .62 to .90 with a mean of .75 were all over the criterion (.50) indicating linear relationships between the items (indicators, endogenous variables) and factors (exogenous latent variables). [26] The values of Theta Delta from the variance/covariance matrix ranging from .60 to 1.39 with mean of .75 indicating reasonable average of measurement errors. The inter-factor coefficients (Phi values) among each pair of factors ranging from .29 to $.78(M=.54)$ demonstrated reasonable relationships between each pair of factors. [26]

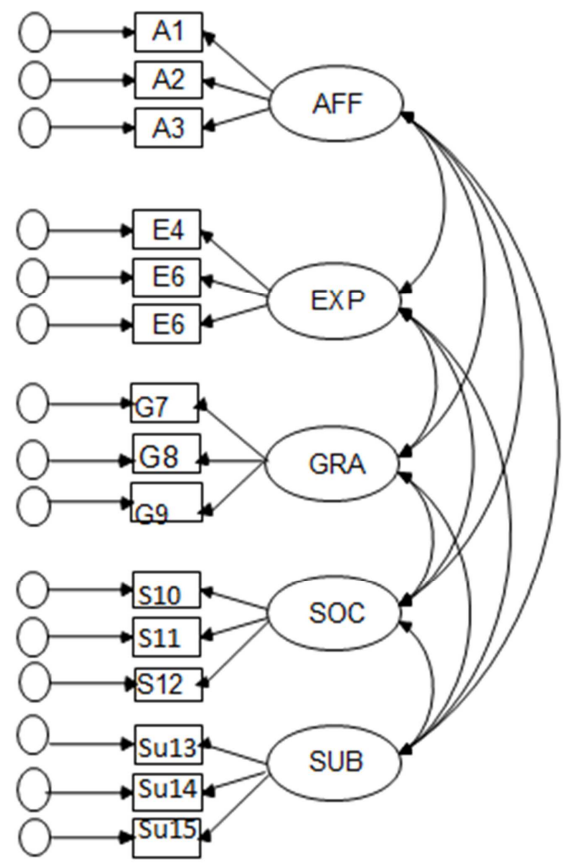

Figure 2. The AMOS diagram shows the relationships of latent variables for $M_{5}$ with the related 15 indicators in CFA. 


\subsection{Overall Model Fit Indexes}

The overall model goodness of fit indexes were further interpreted: (a) absolute measures; $\mathrm{X}^{2}=290$ was significant $(p$ $<.05)$ and Goodness of Fit Index (GFI) was .95 reflecting that more than $90 \%$ of the total variance and covariance were explained by the model, and Root-Mean-Square Residual (RMSR) was .036 indicating mean residual correlation was below .05 limit and acceptable; [26] (b) parsimonious fit measures; Adjusted-Goodness of Fit Index (AGFI, .93) was greater than the standard and $\mathrm{X}^{2} / d f=3.63$ was reasonable based on the sample size of this study; [26] (c) incremental fit measures; the value of Non-Normed Index (NFI, .92) comparing incremental fit of model to null model was acceptable. [26] In addition, the Incremental Fit Index (IFI, .71) and Comparative Fit Index (CFI, .71) were interpreted satisfactorily due to the sample size and normality of data. [28] The coefficients of Root Mean Square Error of Approximation (RMSEA, .032) and Akaike's Information Criterion (AIC, 370) testing parsimony in an assessment of model fit demonstrated acceptance of IMARS. [26, 27]

\subsection{Testing Validities}

In addition to content (face) validity of IMARS established in the first step of instrument development, the additional construct validities including convergent and discriminant validities were examined. The convergent validity of 5-factor model were interpreted: (a) the factor loadings were all significantly greater than .50 standard (see Table 2 ) indicating sufficient variances explained by the observed indicators; [26] (b) the variance-extracted measures reflecting variance contributed indicators were used to test five latent structure. All coefficients $(\mathrm{AFF}=.82, \mathrm{GRA}=.76, \mathrm{EXP}=.77, \mathrm{SOC}=.72$, and $\mathrm{SUB}=.73$ ) exceeded the criteria indicating all items were qualified indicators representing the latent structure; [26] and (c) the average variance-extracted (AVE) was computed for the each of the five constructs (Table 2). AVE values of AFF (.68), GRA (.59), EXP (.60), SOC (.66), and SUB (.58) were all greater than .50 with satisfactory convergent validity. [26] The discriminant validity was tested by comparing AVE values to squared correlation coefficient $\left(\mathrm{R}^{2}\right)$ of each pair of the five constructs. The value of AVE for each factor was all greater than the squared correlation $\left(R^{2}\right)$ for the related factors which indicated acceptance of discriminant validity of the model. [26]

\subsection{Testing Reliabilities}

The reliabilities (internal consistency) of 5-factor IMARS were examined utilizing alpha reliability and composite reliability. [26] The alpha reliabilities ranging from .85 to .66 (Table 3 ) with a mean of .75 were marginally accepted, and indicated a sound internal consistency of each of five factors and supported the internal reliability of the construct. [26] The composite-reliabilities for five constructs were .85 for AFF, 70 for GRA, .82 for EXP, .72 for SOC, and .70 for SUB with mean of .76 that met .70 standards. [26] Both results provided a decent satisfaction of internal-consistency reliabilities for 5-factor Model of IMARS. Among 15 items (indicators) the highest mean scores were found on the items of S10 $(M=6.16), \mathrm{S} 11(M=5.98), \mathrm{G} 7(M=5.76)$, and G8 $(M$ $=5.64)$, showing the higher rated indicators. S10 was the most significant motivational item compared to $\operatorname{Su} 13(M=4.46)$ as the lowest one for the auto-racing spectators (Table 1). The mean scores of the factors were 5.22 (AFF), 5.59 (GRA), 4.75 (EXP), 5.67 (SOC), and 4.70 (SUB), respectively. The factor of SOC was rated as the highest one and SUB was scored as the lowest factor of IMARS (Table 2).

Table 3. Upper: CFA Standardized Estimates (AX), Theta Delta ( $\Theta \Delta)$, Standard Errors (S.E) of IMARS; Lower: Comparison of CFA Goodness of Fit Indexes between 5-Factor Models $(N=650)$.

\begin{tabular}{|c|c|c|c|c|c|c|c|c|c|c|c|c|c|c|c|}
\hline Item & A1 & A2 & A3 & E4 & E5 & E6 & G7 & G8 & G9 & S10 & S11 & S12 & Su13 & Su14 & Su15 \\
\hline$\Lambda \mathrm{X}$ & .89 & .81 & .84 & .75 & .85 & .90 & .71 & .62 & .78 & .75 & .78 & .65 & .75 & .66 & .62 \\
\hline$\Theta \Delta$ & .62 & .79 & .74 & 1.00 & .86 & .65 & .59 & .74 & .86 & .72 & .61 & .60 & 1.35 & 1.39 & 1.19 \\
\hline Index & $X^{2}$ & $d f$ & $\mathrm{X}^{2} / d f$ & GFI & AGFI & CFI & NFI & IFI & RMSR & AIC & & & & & \\
\hline
\end{tabular}

\section{Discussion}

The study has fulfilled two research purposes: (a) the essential motivation factors specified to auto racing spectators were explored based on self-determination and intrinsic and extrinsic motivation theories; and (b) the 5-factor model of IMARS with satisfactory content and construct validities and reliabilities has been confirmed with the statistical evidences. The 5-factor model should be workable due to fact of that several strengths appear measuring specific motivation factors for the spectators of auto racing sport. First, it has relied on both traditional (intrinsic and extrinsic motivation) and SDT theories to develop the motivation constructs. Second, it was a more appropriately conceptual model explaining spectator motivation. Third, the items and factors represented necessary domains of fans' motives or the incentives endorsed by the NASCAR organizers. Additionally, the instrument had satisfactory statistic support for its validities and reliabilities and would be suitable to measure specific motivational determinants of auto racing spectators.

The 5-factor IMARS contains two motivation factors, 'affiliation' and 'substance' as related to the traditional motivation theories and previous research findings. 'Affiliation' is generally viewed as an intrinsic motive that reflects what the individuals want to do. [7, 14, 25] The spectators of NASCAR rated this intrinsic motive highly $(M=$ 5.22) and shared it in common with most of other fans in different sports. The construct of 'affiliation' owns stably statistical support with strong construct validities and reliability (e.g., average $\mathrm{FL}=.75$, variance-extracted measure 
$=.82, \mathrm{AVE}=.68, \alpha=.85$ ) exceeding the related criteria. [26] This is consistent with results of Wann and his colleagues who found '(group) affiliation' occupied a prestige position of factors in their SFMS. Kahle and his colleagues found that 'affiliation' (worded as 'attachment of a team') was a highly agreed motive by the respondents of the survey. [12, 13] Milne and McDonald confirmed that 'affiliation' was one of the most influential factors constructed in their Motivation Scale for Consumers. While this essential motive was ignored in several psychometric properties (e.g., MSSC, SMS) due to limitations of literature review or empirical experience, the researcher did see its value because of theoretical indications from previous research and feedbacks from NASCAR event management regarding loyal auto racing fans. [14]

'Substance', on the other hand, is a representative of extrinsic incentive that could pull interests of individuals to the racetracks. Due to its substantial attraction to the lower stage audiences (novice, media consumers), many event managers have utilized material benefits to recruit new customers or keep current fans staying loyal. The 'substance' was found as the lowest rated factor $(M=4.70)$ with marginal acceptance of construct validities and reliability indicating a need to improve in item generation and statistical significance. [26] Item Su13 (take advantage of discount for their ticket and parking) was the lowest rated item. Perhaps NASCAR fans were more interested in other incentives rather than the discounted items or they might see a small amount discount that would not bring a distinguish value compared to other incentives such as taking a photo with the famous driver or winning a large lottery during the auto racing events. This factor might not be constantly impactful to many fans unless a value-added incentive would be given to enhance attractiveness. Similar findings were found in several studies. Either the 'utilitarian incentive' (substance) was the lowest factor for membership of sport organizations, 'economic' (substance) showed lesser preference by the sport fans, and 'economic factor' was placed at the bottom of all motivational factors in the study of Trail and James. [11, 13, 15] However, the event managers, in practice, have kept endorsing material incentives in the forms of discounted tickets, free samples for extended product or service (e.g., free parking, complementary seats), and on-sale t-shirts or hats with printed logos or drivers' pictures for providing a variety of incentives to attract different spectators who have discrepant interests and desires. [1]

It is important to note that three motivation factors, 'gratification', 'socialization', and 'experience' were redefined deriving from SDT components. 'Socialization' $(M$ $=5.67)$ and 'gratification' $(M=5.59)$ were the highest rated factors by the auto racing fans. The AVE (.59) of 'gratification' is greater than the squared correlation coefficient $\left(\mathrm{R}^{2}\right)$ with 'socialization' in discriminate test. [26] However, the internal consistency reliabilities of these two factors were .80 and .72 higher the cutoff point that were acceptable. [26] This might be attributed to a strong correlation between the factors. As 'gratification' was the self-determination related motivation factor, it reflects that individuals could decide whether they want to reward themselves or appreciate others after carefully determining external information and the degree of inner drive toward action to watch the sport events. The factor of 'escape' as an element of gratification was provided in the study of Trail and James. $[6,15]$ They indicated that sports fans were more often to escape from day-to-day activities and gratify themselves a relaxation time by attending the sport events. The finding of 'gratification', however, was opposite to the study of Chen who overlooked appreciation and rewarding oneself in the panel of incentive factors for the members of sport organizations. [10] It might be explained that many auto racing fans or business organizations were likely to take advantage of the sport events to retreat themselves from tired work as self-rewarding or utilize the opportunity to treat others (business partners, close colleagues) as a way of appreciating their cooperation or contribution.

'Socialization', however, was viewed as a self-judged motivation because this psychological force was initiated from social needs of human with desires to meet other people, and appreciate sincere invitations offered by those who have had a close relationship (e.g., family members, old friends). Item S10 stated as 'have an enjoyable time with my family and relatives' and item S11 worded for 'socialize with the fans, friends, and peers' were the highest rated items in the domain of 'socialization'. It is not surprising that these common motivation elements of sport fans have been evidenced with other motivation inventories (e.g., MSSC, FAM, MSC) due to the nature of sport event as social platform for the people and interactive chance in the crowded sporting events. Milne and McDonald indicated that 'social facilitation' (socialization) motivation was critical to attract crowed to the sport stadium. [14] Regardless of the economic status of certain individuals, some would not function well psychologically without social facilitation and interaction. Trail and James agreed that "interacting with other fans is a very important part of being at games" (p. 120). [15] Dwyer and Kim, and Fink and Barker supported that social activities such as sport events provided great opportunities for individuals to interact others and facilitate their friendship, professionalism, and spectatorship. $[16,24]$

'Experience' was additional motivation factor reflecting two components, learning something new by observation and advancing informative outcomes. The motivational force could be sparked up depending on autonomy and cognitive evaluation of individuals toward benefits of the knowledge and information for their personal growth and career advancement. The more positive experience obtained from the previous competitive events, the higher motivation would be for the spectators to return back the racetracks. The factor of 'experience' had a strongly statistical support with satisfactory construct validity and reliability exceeding the related criteria. Interestingly, 'experience' was rated relatively lower than 'gratification' and 'socialization'. Possibly many respondents were still younger (55\% of participants were under 35 in this study) in their life learning stage of pursuing their personal and social growth. They would be likely to follow something or someone they like such as a preferred 
sport and a favorite driver or team in NASCAR competitions. At same time, obtaining updated knowledge and information about the sport in order to enrich their life experience would have served their best interests. This result was similar to other studies that 'informative incentive' was rated highly by the members of sport organizations, and 'information' was more valuable to the sport fans than other motivational factors to cause the individuals to involve in sport consumption. [10, 16] Supportively, the 'acquisition of knowledge' was found as the first important motivation factor relating to the definition of 'experience' that appeared consistently for this important variable of the study. [15]

\section{Conclusion}

The 5-factor IMARS elaborates necessary multidimensional (intrinsic and extrinsic, self-determined) factors of consumer motivation in auto racing sport with consideration of individuals and social context that impact the behavior of sport spectators. 'Socialization' and 'gratification' remains constant and these variables would be essential in the analyses of consumer motivation. Moreover, ignorance of 'affiliation' and 'experience' factors could results failure of recruiting new spectators and loosing current fans on their retention database. Even if 'substance' was rated lower compared to other motives, it still has its value in the incentive system. The contribution of each factor to motivate the spectators could have combined efforts and determined through ratings given by the respondents that might be in a notion of ' $A=[\Sigma(\overline{\mathrm{x}} 1 \ldots \mathrm{iN}) \div \mathrm{Ni}] \div P \geq .65$ '. Where $(A)$ is attendance of spectators, and $[\Sigma(\overline{\mathrm{x}} \mathrm{i} 1 \ldots \overline{\mathrm{x}} \mathrm{iN}) / \mathrm{Ni}]$ represents that the summarized item means in the factor is divided by number of items $\left(\mathrm{N}_{\mathrm{i}}\right)$, and the value is then divided by maximum point $(P)$ in the scale. It might be a meaningful factor if the result would be or greater than .65. However, this attempted expression based on the empirical observation of research must have a further examination. While individuals keep developing and being motivated to progress through pursuing satisfaction of their life in the hierarchy of human needs and ensuring security of personal growth, improved economic stability and social maturity would allow more individuals to pursue their needs of leisure by taking advantage of sport events. [9] It is a fact of human needs for healthy growth to provide more opportunities of productivity for sport industry, especially for NASCAR. IMARS as the first attempt to test NASCAR fans' motivation has filled a void of research in this population and met the demand of sport-specific instrument in auto racing sport. It could serve as an initiative point to generate more attention or effort to this large revenue producing sport for continuous discussion and discovery.

While several caveats must be mentioned in this study (e.g., 'substance' was not as strong as other factors in the value of AVE, composite reliabilities for 'gratification' and 'socialization' should gather more attention), the 5-factor IMARS demands a test-retest procedure to ensure best quality of psychometric property. As meaningful implications the study provided a measurement product for utility of auto racing sport industry; IMARAS as a valid and reliable tool could be used by the NASCAR marketing professionals to gather relative information of their consumers as regards to specific needs and wants for NASCAR events. The event managers could apply the validated instrument or adopt some factors or items into their event-focused survey to obtain feedback for their advancement of marketing plans. Except for their traditional promotion strategies, out-of-box consideration should be given to how the fans' identification would be better facilitated as related to their commitment, and what social events could be integral into the weekend long event to meet their demands of enhancing socialization and enriching spectatorship experience. Referring findings of this study, the decision makers may redesign their incentive packages for recruiting more novices, retaining early stage spectators, and making them repeated customers by providing positively self-determined experience in addition to attractive nature of the sport itself.

Future study in this avenue could be directed to the advancement of instrument with extended domains and items. Testing different samples of NASCAR fans by using IMARS for measurement generalizability might be worth. Applying IMARS to examine spectator motivation for different sports (NFL, boxing) would provide valuable results of comparison as many sports have shared some characteristics in common (e.g., aggressive sports). Investigating relationship between fans' motivational patterns and their perceptions of NASCAR image, sponsorship, and brand loyalty should be meaningful as well. Examining how the culture of the fans among several sports could bring important indications to support theories of social diversification would be an interesting extension of spectator motivation. Research endeavors to test differences of auto racing spectators by examining variables of age, gender, education, and purchasing power deserve continuous attention as well.

\section{References}

[1] Humphrey, R. R., \& Ruseski, J. E. (2009). Estimates of the dimensions of the sports market in the US. International Journal of Sport Finance, 4 (2), 94-113.

[2] NASCAR. (2012). The National Association for Stock Car Auto Racing. Retrieved from www.nascar.com.

[3] Bernthal, M. J., \& Regan, T. H. (2004). The economic impact of a NASCAR racetrack on a rural community and region. Sport Marketing Quarterly, 13 (1), 26-34.

[4] Schwartz, J. T., Isaacs, J. P., \& Carilli, A. M. (2007). An empirical investigation of the efficiency of the NASCAR points competition. Journal of Sports Economics, 8 (6), 633-641.

[5] Deci, E. L. (1975). Intrinsic motivation. New York: Plenum Publishing.

[6] Deci, E. L., \& Ryan, R. M. (1985). Intrinsic motivation and self-determination in human Behavior. New York: Plenum. 
[7] Deci, E. L., \& Ryan, R. M. (2000). "The 'what' and 'why' of goal pursuits: Human needs and the self-determination of behavior." Psychological Inquiry, 11 (4), 227-268.

[8] Medic, N., Mack, D. E., Wilson, M., \& Starkes, J. L. (2002). The effects of athletic scholarships on motivation in sport. Journal of Sport Behavior, 30 (3), 292-306.

[9] Leidl, D. (2009). Motivation in sport: Bridging historical and contemporary theory through a qualitative approach. International Journal for Sport Science and Coaching 2 (4), $155-175$.

[10] Chen, L. (2004). Membership Incentives: Factors affecting individuals' decisions about participation in athletics-related professional associations. Journal of Sport Management, 18 (4), 143-173.

[11] Wann, D. L. (1995). Preliminary validation of the sport fan motivation scale. Journal of Sport and Social Issues, 19 (4), 377-396.

[12] Wann, D. L., Schrader, M. P., \& Wilson, A. M. (1999). Sport fan motivation: Questionnaire validation, comparisons by sport and relationship to athletic motivation. Journal of Sport Behavior, 23 (1), 114-139.

[13] Kahle, L. R., Kambara, K. M., \& Rose, G. M. (1996). A functional model of fan attendance motivations for college football. Sport Marketing Quarterly, 5 (4), 51-60.

[14] Milne, G. R., \& McDonald, M. A. (1999). Sport Marketing: Managing the exchange process. Sudbury, MA: Jones and Bartlett Publishers.

[15] Trail, G. T., \& James, J. D. (2001). The motivation scale for sport consumption: Assessment of the scale's psychometric properties. Journal of Sport Behavior, 24 (1), 108-127.

[16] Dwyer, B., \& Kim Y. (2011). For love or money: Developing and validating a motivational scale for fantasy football participation. Journal of Sport Management, 25 (2), 75-83.

[17] Kim, Y. K., \& Trail, G. (2010). Constrains and motivators: A new model to explain sport consumer behavior. Journal of Sport Management, 24 (2), 190-210.
[18] James, J. D., \& Ross, S. D. (2004). Comparing sport consumer motivations across multiple sports. Sport Marketing Quarterly, 13 (1), 17-25.

[19] Amato, C. H., Peters, C. L., \& Shao, A. T. (2005). An exploratory investigation into NASCAR fan culture. Sport Marketing Quarterly, 14 (2), 71-83.

[20] Hugenberg, L., \& Hugenberg, B. (2008). NASCAR Fans In Their Own Words. In Hugenberg, L., Aaridakis, P., \& Earnheardt, A. (Eds). Jefferson, NC: McFarland and Co.

[21] Sartore-Baldwin, M., \& Walker, M. (2011). The Process of organizational identity: What are the roles of social responsiveness, organizational image, and identification? Journal of Sport Management, 25 (5), 489-505.

[22] Levin, A. M., Beasley, F., \& Gamble, T. (2004). Brand loyalty of NASCAR fans towards: The impact of fan identification. International Journal of Sports Marketing and Sponsorship, 6 (1), 11-21.

[23] Allmen, P. V. (2001). Is the reward system in NASCAR efficient? Journal of Sports Economics, 2 (1), 62-79.

[24] Fink, J. S., \& Parker, H. M. (2009). Spectator motives: Why do we watch when our favorite team is not playing? Sport Marketing Quarterly, 18 (3), 210-217.

[25] Wann, D. L., Grieve, F. G., Zapalac, R. K., \& Pease, D. G. (2008). Motivational profiles of sport fans of different sports. Sport Marketing Quarterly, 17 (1), 6-19.

[26] Hair, J. F., Black, B., Babin, B., Anderson, R., \& Tatham, R. (2010). Multivariate data analysis (6 $6^{\text {th }}$ ed.). Upper Saddle River, NJ: Prentice-Hall.

[27] Finch, W. H., Immecus, J. C., \& French, B. F. (2016). Applied Psychometrics with SPSS and AMOS, Information Age Publishing.

[28] Fu, L., \& Bentler, P. M. (1999). Cutoff criteria for fit indices in covariance structure analysis. Structural Equation Modeling, 6 (1), 1-55. 